\title{
The court's role in life and death decisions
}

\author{
by Laurence Oates
}

The Official Solicitor considers the involvement of the courts - and, where appropriate, the part played by him - in cases requiring end of life or life-saving decisions.

$\mathrm{T}$ his is a subject not only of some legal interest but also giving rise to some questions with a moral, ethical or religious dimension. Emotions can also be aroused. During the height of the conjoined twins case in 2000 (Re: A (Children) (Conjoined Twins: Surgical Separation [2001] 2 WLR 480) one commentator likened the position of Mary, the weaker of the two whom I was representing, to being on death row. The central dilemma of that case was that without the intervention of the courts both of the conjoined twins would have died within a reasonably short time frame. We are all destined to die, the questions being how and when. This article considers the circumstances in which the High Court in England and Wales has a part to play in that event; and also in making life-giving or life-saving decisions.

Each year there are about 20 cases in the Family Division of the High Court in England and Wales concerning whether medical procedures should or should not be carried out on people who are unable, or refuse, to consent to the treatment in question. There are broadly three types of case:

- medical opinion is that a particular course of treatment will save life - this includes whether a blood transfusion should be given, a caesarean section should be performed, or even whether a heart transplant should be ordered against the known views of the child patient;

- medical opinion, supported by those caring for the patient, is that a particular operation should be carried out to enhance the quality of life of the patient or to ensure improvement or prevent deterioration in his or her physical or mental health - the question of whether sterilisation of a patient who is unable to consent should be carried out falls into this category; and

- medical opinion is that consistently with the duty owed to the patient an aspect of treatment should be terminated so as to allow that patient to die peaceablythis concerns the question of whether artificial feeding and hydration for a patient in a permanent vegetative state should be withheld or withdrawn.
In accordance with the President's Direction of 14 December 2001 (Declaratory Proceedings concerning Incapacitated Adults: Medical and Welfare Decisions) a number of these cases, and certainly those in the third category, will be determined by the President. I am brought in to represent those patients who need a guardian ad litem (if 'family proceedings' under the Family Proceedings Rules 1991) or litigation friend (if 'civil proceedings' under the Civil Procedure Rules 1998) primarily either children or mentally incapacitated adults or I may be asked by the court to assist as an amicus (now re-styled by the Lord Chief Justice as 'Advocate to the Court').

This seminar also encompasses the issues raised by the recently concluded Diane Pretty case $(R$ (Pretty) v Director of Public Prosecutions [2001] 3 WLR 1598). Neither the President nor I were involved in that case and it falls outside the categories I have referred to above. Its special features for our present purposes are that it was not a case about medical procedures - the person who wished to assist the motor-neurone disease sufferer Mrs. Pretty in her suicide was not a medical practitioner but was her husband and the method by which it was proposed that he should act was not specified - and it concerned someone who was fully mentally competent to decide what to do within the law for herself (albeit that she was not physically capable of bringing her own life to an end).

One point to draw out having referred to that case is that the circumstances in which in judicial review proceedings the courts may be called upon to review decisions by others which may have life or death consequences for the person affected are many and varied. The cases with which I am primarily concerned are cases in which the courts have the original fact-finding and decision-making jurisdiction. Where a party whose decisions or acts are in question and who may or may not be acting in the best interests of an incapacitated person is a public authority, an interesting interface may arise between the judicial review and original jurisdictions. Munby J, who happens to be a Family Division judge and 
a judge assigned to the Administrative Court, has in $A v A$ Health Authority and Ors (etc) [2002] EWHC 18 (Fam/Admin) thrown some light upon this interface and when public law remedies should be sought.

\section{JURISDICTION}

As a precursor to considering some of the issues, we should first establish the jurisdictional basis upon which life and death issues become the responsibility of the courts. It is founded in the long-recognised duty of the Crown as parens patriae to protect the person and property of its subjects and particularly those unable to look after them. The judges have inherently exercised this power and duty, so far as children are concerned (since 1660 either in Chancery or in the Family Division). In practice it has now been supplemented, and to a large extent superseded, by the Children Act 1989, which is a near-comprehensive codification of the law relation to children. Any proceedings concerning the welfare of a child can be brought under that Act and the welfare of the child will be the paramount consideration for the court. The other prime beneficiaries of the Crown's parens patriae power were lunatics (as then described). The historical evolution of that power as it relates to them is somewhat different.

Following the Restoration of the Monarchy in 1660, the Crown's parens patriae power in relation to lunatics and other incompetent adults was assigned by Letters Patent under the Great Seal (and latterly by Warrant under the Sign Manual) to specific individuals - namely the Lord Chancellor and designated Judges. At the time that the Mental Health Act 1959 came into force the latest Warrant was revoked. The 1959 Act was largely a codification of the law in this area and it provided a statutory framework to have effect with respect to the reception, care and treatment of mentally disordered patients, the management of their property and other related matters. The question with which the courts had subsequently to grapple was whether the inherent jurisdiction had survived in any shape or form or whether it had been replaced in the statutory code. This was decisively answered by the House of Lords in Re: F (Adult Patient: Sterilisation) [1990] 2 AC 1. The Family Division has inherent jurisdiction to make declarations as to the lawfulness of treatment, which is in the best interests of incompetent adults unable to decide for them. This principle has since been extended to other welfare decisions.

The two separate jurisdictions is an important point to draw out now. Cases concerning the compulsory detention and treatment for mental disorder (as widely defined) are to be determined under, and in accordance with, the Mental Health Act. That provides its own procedures, including circumstances in which there can be a review by a Mental Health Review Tribunal. They will generally only reach the High Court upon an application for judicial review. Cases concerning all other aspects of medical treatment of a mentally incompetent adult, irrespective of whether he/she is a patient under the Mental Health Act, are determined under the inherent jurisdiction.

One example where different outcomes have been reached in different jurisdictions concerns the forcefeeding of prisoners. As will be seen, consistent with principle established in the inherent jurisdiction, a detained adult prisoner of sound mind can, and must, be allowed to starve himself/herself to death - see Home Secretary for the Home Department v Robb [1995] Fam 127. However, in $R v$ Collins and Ashworth Hospital Authority, ex parte Brady [2000] Lloyd's Law Rep Med 355, a judicial review case concerning the Moors' Murderer Ian Brady's attempt to starve himself to death, the issues arising there were whether the force feeding was 'medical treatment' and was 'for the mental disorder from which [the applicant] is suffering'. In upholding Ashworth Hospital's force-feeding, and rejecting Mr Brady's submissions that his intention to starve himself to death was unrelated to his mental disorder and was the rational decision of a competent person, Maurice Kay J decided that in the judicial review proceedings he did not have to resolve these submissions as a matter of fact but that in any event on the facts as before the court he was against Brady on both points. This case pre-dates the implementation of the Human Rights Act 1998. It has since been doubted in the Court of Appeal whether the same decision would be reached today ( $R$ (Wilkinson) v Responsible Medical Officer, Broadmoor Hospital and others (CA 22 October 2001)).

That appeal raised an interesting point as to how the judicial review of the decision reached under the Mental Health Act procedures should be conducted in a way compatible with the patient's human rights. The appellant was a 69-year-old mental patient who had been detained at Broadmoor for 34 years. He vigorously opposed, and physically resisted, treatment by way of anti-psychotic medication. His responsible medical officer considered that nonetheless the treatment should be given to alleviate or prevent a deterioration of his condition, and that the risk to his health in so doing was negligible. A 'second opinion appointed' doctor agreed and the conditions under the Act for the compulsory administration of the treatment were met. In the judicial review proceedings the appellant submitted a report from an independent consultant psychiatrist to diametrically opposite effect namely, that the anti-psychotic medication would not help and in the light of this resistance could lead to sudden cardiac death. The point determined in the appeal was that, notwithstanding the new wider approach to judicial review developed in such cases as $R$ (Alconbury) $v$ Secretary of State for the Environment, Transport and the Regions [2001] 2 All ER 929 and $R v$ Secretary of State for the Home Department, ex p Daly [2001] 2 WLR 1622, in order to ensure that his human rights were upheld the court must hear direct oral evidence from the doctors concerned to reach a view as a matter of fact on who was right. 


\section{INCAPABLE ADULTS}

Whenever the High Court is called upon to exercise its inherent jurisdiction in relation to an adult patient, it will have before it two issues. The first is whether the adult patient is capable or not of reaching his/her own decision on the treatment in question and therefore of giving a valid consent or refusal; the second is, if not, what is in his/her best interests? The issue of capacity to consent depends upon whether the patient fully understands the nature of the medical interventions proposed, their reasons, and the consequences of submitting or not submitting to them (see Re: MB (Medical Treatment) [1997] 2 FLR 426). I should pause to point out that the tests for capacity for different purposes are different. My involvement in representing a party in such proceedings can only arise when that party is incapable, by reason of mental disorder of managing and administering his property and affairs (see the slightly differently worded tests set out in Family Proceedings Rules 1991, rule 9.1; Civil Procedure Rules 1998, Part 21). I invariably require evidence from a psychiatrist or psychologist who has assessed the patient and can give an opinion whether that test is met; and, if it is, whether in applying the $\operatorname{Re} M B$ test to the particular decision in question the patient lacked the capacity to consent.

The fact that a patient has been sectioned under the Mental Health Act and is subject to compulsory detention and treatment is neither determinative of his/her capacity to manage property and affairs nor to consent to treatment. The best example of this is $\operatorname{Re} C$ (Adult: Refusal of Medical Treatment) [1994] 1 WLR 290 concerning a patient at Broadmoor with chronic paranoid schizophrenia and with gangrene in his right foot. The medical evidence was that he would die imminently if the leg was not amputated below the knee, and he was given no higher than a 15 per cent chance of survival if not. He refused to consent to amputation but agreed to more conservative treatment. Thorpe J held that he had understood and arrived at a clear choice and his refusal was upheld. In the result, as we understand it, he survived and gangrene did not return.

'Best interests' has been judicially defined to encompass medical, emotional, and all other welfare issues. A court should draw up a check-list of the actual benefits and disadvantages and the potential gains and losses, including physical and psychological risks and consequences, and should reach a balanced conclusion as to what is right from a point of view of the individual who is the subject of the proceedings (see Re: A (Male Sterilisation) [2000] 1 FLR 549).

\section{CAPABLE ADULTS}

One important principle I would emphasise is that a competent adult cannot be compelled to undergo lifesaving, or any other, treatment. The clearest example of this principle is St. George's Health Care Trust v S [1999] Fam 26. This case concerned a pregnant lady who would not consent to a caesarean section and the mistaken view held by the hospital authority that her refusal should be overridden, as she must thereby be suffering from a mental disorder because her view was contrary to the medical opinion of what was in her best interests. The case is also authority for the proposition that a competent adult can refuse treatment, which would save an unborn foetus. The foetus, up until the moment of birth, does not, in law, have any separate interest capable of being taken into account. This is all part of the right of an adult to autonomy, and a reflection that subject to the statutory prohibitions contained in the Abortion Act 1967 and/or the Infant (Life Preservation) Act 1929 the law's protection extends only to a life in being.

This principle has, since this lecture was first given, been graphically re-affirmed by the President in $M s B v$ An NHS Hospital Trust [2002] EWHC 429 (Fam). A competent patient's refusal to consent to life sustaining treatment (in this case artificial ventilation) must be respected. Doctors should not confuse the question of capacity with the nature of the decision made by the patient, however grave the consequences.

\section{ADVANCE DIRECTIVES}

Consent or refusal by an adult may have been furnished in advance through an advance directive. In such a case, the question will be whether the adult was capable at the time of giving that directive and whether it is applicable to the circumstances, which have now arisen. If there is reason to doubt the validity or applicability of the advance directive - for example, it may sensibly be thought not to apply to the particular life threatening circumstances that have arisen - the court will consider the advance directive as a part of the evidence of what is in the patient's best interests. One example of an advance directive is in the case of Re AK (2000) 58 B.M.L.R. 151. This concerned a nineteen and a half year old motor-neurone disease sufferer. Its unusual feature, so far as this disease is concerned, and which points to a contrast with the Pretty case, was that before a conclusive diagnosis of motorneurone disease had been made this patient had suffered a respiratory arrest, and was now being kept alive by artificial ventilation. He had reached the stage in the progression of the disease that he could only communicate through movement of an eyelid. He told his carers by this means that he wished his ventilation to be stopped once he could no longer communicate at all. Hughes J granted a declaration that it was lawful to do so, it being on the contrary unlawful to continue the invasive treatment in the insertion of a tracheotomy tube without his consent.

\section{CHILDREN}

A second principle, in contrast to the first, is that a child can be ordered to have life-saving, or any other, treatment if it is in his or her welfare interests notwithstanding the child's or parents' views. This enables parental opposition to treatment to be overcome. Thus an adult Jehovah's Witness can refuse a blood 
transfusion for him/herself but the courts will take the decision if it is needed to safeguard the welfare of his/her child. In the case of Re: C (A child)(HIV Testing) [1999] 2 FLR 1004 Wilson J. held that notwithstanding the opposition of both parents who believed in alternative medical remedies and not in the generally accepted current medical opinion as to the causes and diagnosis of aids, it was overwhelmingly in the interests of the child that those parents and doctors caring for her should know whether she had contracted the virus. He ordered that a blood sample should be taken from the child. Those of you who were at the time following the news reports in relation to that case will be aware that the parents fled the country with the child before any blood sample could be taken and have not been seen since. I shall look further into the weight to be given to a parental refusal when I come to discuss the conjoined twins case.

The views of the child can seemingly be overridden however mature or otherwise competent that child may be. The courts have developed the doctrine of 'Gillick competence', so-called because it arose in the case of Gillick $v$ West Norfolk and Wisbech Area Health Authority [1986] AC 112. That case concerned the right and ability of a 14 year old to seek contraceptive advice regardless of parental opposition. By virtue of s. 8 of the Family Law Reform Act 1969 children of 16 and over are able to give consent to medical treatment as if they were adult. This enables a competent child over 16 years of age to override a refusal by his/her parents without the courts' intervention. But it does not follow that the refusal to give consent of a competent child will be determinative in the same way as it would be if adult. The case of Re: $M$ ( $A$ child) (Medical Treatment: Consent) [1999] 2 FLR 1097 is a stark example of overriding the views of a mature adolescent. That case concerned a fifteen and a half year old girl who was diagnosed with a heart disease, which had afflicted her quite suddenly, and which required, if she was to be saved, a heart transplant. Johnson J. in deciding to order the heart transplant was able to draw some support from the evidence that she was confused as a result of the events, which had so quickly overwhelmed her and the question of Gillick competence, was not raised. I would suggest that the Family Division Judges will continue to act in accordance with a child's welfare interests and find that it is overwhelmingly in the child's welfare interests to be kept alive irrespective of how competently (in terms of understanding and assessing the issues) that child wishes to embark upon or maintain a course of conduct to the opposite effect. There is, however, quite a contrast between the position at any time immediately prior to one's eighteenth birthday and thereafter. There is also a question, yet to be litigated, whether the protection in Art. 5 of the ECHR against deprivation of liberty have any application to the detention, which may be required in order that compulsory treatment can be given.

\section{ASSISTING THE TERMINALLY ILL}

I should take together my third and fourth principles, which concern treatment, which may hasten death. The first of these is that medical treatment may be administered to a terminally ill person to alleviate pain although it may hasten death, but medical treatment may not be given intended to bring about death. The second, however, is that subject to judicial authority it is permissible to cease to take active steps to keep a patient in a permanent vegetative state alive. The President (or nominated judge) can, and does, declare lawful the withholding and withdrawal of artificial nutrition and hydration from such patients.

Both these principles derive from Bland (Airedale NHS Trust $v$ Bland [1993] AC 789) as recently confirmed by Pretty (cited above). The Bland case arose out of the Hillsborough football tragedy, at which the victim was crushed almost to the point of death. Whilst retaining brain stem activity (the point at which life ceases) he entered the permanent vegetative state. The House of Lords upheld a declaration that it would be lawful to withhold further life-prolonging treatment and care from him, namely continued artificial nutrition and hydration, as being in his best interests peaceably to die, whereas the converse of keeping him alive would have been futile. This principle has been held by the President to be compatible with the Human Right Act (NHS Trust A v M; NHS Trust $B v H$ [2001] 1 FCR 406. The Pretty case is authority for the proposition that there is no positive obligation upon a State under the European Convention on Human Rights to allow for euthanasia or assisted suicide. A number of questions of interest arise.

The first of these related propositions takes us into the doctrine of double effect. It is perfectly permissible to, say, administer a dose of diamorphine intending the one consequence (the alleviation of pain) but reasonably foreseeing the other (that death will be hastened). The Rubicon is crossed if by this intentional act the hastening of death is intended. It can be appreciated that there may be a fine dividing line between the legal concepts of intention and reasonable forseeability. This dividing line is made more difficult in that in the criminal law intention is more widely defined than in medical law, and would encompass the administration of a dose of diamorphine virtually certain to cause death. Yet it is clearly an important principle that the intentional hastening or causing of death by a positive act is not permissible unless or until Parliament decrees that it is and defines the circumstances in which it is to be permitted and the safeguards which should be applicable to it.

The second of these related propositions introduce the distinction between positive acts causing (and intending) death and the negative act of withdrawing or withholding treatment, which artificially prolongs life (and by doing so will inevitably and intentionally result in death). I have used 
my words carefully because in such a case an accurate analysis needs to be conducted as to both causation and intention. The distinction has, however, been criticised; both by doctors who find the distinction between 'positive' and 'negative' acts difficult to draw in practice, and by academic legal writers (see e.g. J Keown 'Restoring moral and intellectual shape to the law after Bland', (1997) 113 LQR 481). Their Lordships themselves in Bland were understandably anxious about the intellectual robustness of the distinction between death brought about by an omission, on the one hand, and death caused by a positive act, on the other (see in particular remarks by Lords Mustill, Browne-Wilkinson and Lowry). The distinction was one of the issues, which caused great difficulty in the conjoined twins case (see below). In my view, it allows the President, or nominated Judge, to do justice in those cases in which prolongation of life is futile. I was, therefore, anxious to establish that this jurisdiction is entirely compatible with Art. 2. Right to Life (NHS Trust $A_{v} M$; NHS Trust $B v H$ ). It has now been reaffirmed by Pretty. The withdrawal of artificial nutrition and hydration does not constitute 'intentional deprivation of life' within the meaning of Art. 2 as the death follows from the patient's illness or injury; and the positive obligation on the State to provide life-sustaining treatment is confined to those circumstances where, according to responsible medical opinion, such treatment is in the best interests of the patient.

There are a couple of comments I would wish to make. The first is based upon the requirement that the court's sanction is given. Doctors should not assume the lawfulness, even where those close to the patient are of the same view that the artificial nutrition and hydration should be withdrawn. Other circumstances in which doctors consider they are acting in the best interests of their patients in withdrawing or withholding treatment may not be subject to court review. As a matter of general principle, the BMA argues that other situations in which lifeprolonging treatment is not a benefit to the patient should not routinely be subject to review by the courts (Guidance for Decision Making on Withholding or Withdrawing LifeProlonging Medical Treatment, BMJ Publishing 1999). A passive 'do not resuscitate' decision, which does not involve an assault, does not give rise to the same potential legal liability and therefore does not require the court's authority, although unless handled sensitively and in accordance with recommended practice, it may give rise to public concern (or form the basis for a negligence action). My second comment is that the Family Division has not yet been faced with a case of minimal as opposed to no awareness - i.e. not falling within the medically accepted definition of permanent vegetative state - where it may be possible to mount similar arguments as to futility and benefit. In one case the then President Sir Stephen Brown granted a declaration albeit that one paragraph of the Royal College of Physicians' Guidelines for determining the existence of PVS was not met but where he was satisfied that there was no awareness (Re $D$ (Medical Treatment)[1998] 1 FLR 411). I would not wish to predict the arguments I would mount in a case in which the evidence was of some minimal awareness but not of a nature to change the essential balance to be struck in terms of futility in maintaining treatment or best interests that the patient's life should not be prolonged (as may occur in a case in which a patient is diagnosed as being in a 'localising responsive state', which is regarded as a presentation of the vegetative state but which should now more accurately be described as the 'minimal conscious state').

Unfortunately, these issues from time to time arise in the context of what should be the other end of life, in relation to babies or young children. The Royal College of Paediatric and Child Health has issued guidelines, Withdrawing or Withholding Life Saving Treatment in Children, a Framework for Practice, which refer to a 'no chance' situation where a child has such a severe disease that life sustaining treatment simply delays death without a significant alleviation of suffering, thereby rendering such treatment inappropriate. In NHS Trust v D (2000) 55 BMLR 19 Cazalet J was faced with this situation in a severely disabled 19 month old child also suffering from irreversible and worsening lung disease, heart failure, and hepatic and renal dysfunction. The NHS Trust sought an order to the effect that if the child were to suffer a respiratory or cardiac failure or arrest it would be lawful to treat him with palliative care only with a view to easing his suffering and permitting his life to end peacefully and with dignity. On behalf of the child I supported this as being in his best interests. The parents were opposed. The Judge granted the order sought. It is not truly a case of futility as continuing mechanical intervention would have had an effect in prolonging life (a life expectancy of one year at most was forecast). However, in so doing it would increase his pain and suffering and would not therefore be in his best interests. The leading authority in this area is the Court of Appeal's decision in $\operatorname{Re} J$ (A Minor) (Wardship: Medical Treatment) [1991] Fam 33.

\section{THE CONJOINED TWINS}

I have now reached the point when I should discuss aspects of that special one-off case, the conjoined twins (Re: A). I say it was one-off because the facts were so unique. The twins were extensively joined at the pelvis, and each had her own brain, heart and lungs and other vital organs, except for the bladder, which was common, and her own arms and legs. The medical evidence was that Jodie sustained the life of Mary by circulating oxygenated blood through a common artery. Without this assistance, and therefore, if separated, Mary would die. If, however, not separated Jodie's heart would eventually fail and both would die within a few months of birth.

At first instance Johnson J decided the case in favour of ordering separation upon the basis that (a) it was in the 
welfare interests of both twins that it should take place i.e. it was in Mary's best interests in the particular circumstances facing her that her death should be hastened - and (b) the separation procedures would be the equivalent of the negative act of withdrawing lifeprolonging treatment. Both these bases were questionable and not upheld in the Court of Appeal although the decision itself was affirmed. Two of the three appeal Judges accepted my argument that the sanctity of life outweighed any arguments based upon quality of life so that hastening death could not be in Mary's best interests. All three agreed that the proposed operation was a positive act of invasive surgery.

The ratio decidendi of the Court of Appeal is more difficult briefly to define, and the judges did not all say the same thing. For our present purposes I shall quote from the head note in the Family Law Reports (which being in the Family Law arena I prefer to the head note in the Weekly Law Reports):

'.... Where the Court was considering the position of two children, the requirement that the interests of the child be paramount was qualified by the need to have regard to potential detriment for one in the light of the potential benefit for the other. The view of the parents commanded very great respect, but was subordinate to the issue of the child's welfare. Bearing in mind that the weaker twin had, on any view, only a few months to live, whereas the stronger twin has the prospect of a relatively normal life if the operation took place, the least detrimental choice, balancing the interests of these two children, was to permit the operation to be performed. It would be lawful for the doctors to perform the operation, even though it would result in the death of one of the patients, because the doctors would be acting in defence of the stronger twin, who was being killed by the weaker twin. The doctors would not be murdering the weaker twin, because they would be acting in quasi-self-defence, or with the defence of necessity'.

There are certain aspects I should draw out. First, there are two family law points. The first concerns the weight to be given to parental opposition. A strong feature of the case is that based upon their Roman Catholic beliefs both parents maintained their refusal to consent to the operation whilst the case was being heard at first instance and in the Court of Appeal. Their views were in the leading judgment, rightly, described as a very important part of the case. Ward L.J. pointed out that nonetheless the English court had overriding control in the welfare interests of the child; the court was not just a reviewer of the parents' decision in a judicial review sense, but itself had to decide what was right; and where in striking a balance between the welfare interests of the twins it came to one view, the court's view must prevail. This is a strong affirmation of the welfare principle being paramount, the more so as the judgment was reached in a context in which there was a strong body of opinion in favour on ethical and religious grounds of the parents' views.

In support of this approach Ward LJ cited Re $T$ ( $A$ Minor) (Wardship: Medical Treatment) [1997] 1 FLR 502.
This was a decision of the Court of Appeal, including the President, in which, whilst the same principles were adopted, a different outcome was reached. It concerned a one year old baby with a life threatening liver defect, and the unanimous medical opinion was that without a liver transplant he would not live beyond the age of two and half years. His parents refused to consent to that operation and their wish prevailed. In analysing that authority in $R e$ : C (HIV Test) (cited above) Wilson J pointed out that the intervention proposed for the child was unworkable without the parents' consent as the burden of ensuring a successful aftermath was on them. There is a judgment to be drawn on behalf of a child whose parents are implacably opposed to life-saving treatment whether the solution can only be found in a care order, under which the local authority concerned could secure that the necessary treatment took place. The President will tell you how a happy resolution eventually emerged in the liver transplant case in that divorced from the pressure of the litigation parents and doctors reached agreement and a successful operation was undertaken.

The second family law point in the conjoined twins case is the very balancing of the interests of the twins. This led the court into eschewing (in my view rightly) any analysis based upon comparing quality of life, but nonetheless deciding that the balance was to be struck in terms of the worthwhileness of the treatment as compared to no treatment, although whether this avoids all comparison in terms of quality of life is open to argument.

Secondly, there is the criminal law aspect. In order to reach the conclusion that the operation could, and should, lawfully be performed it was necessary to decide that no criminal act in relation to Mary would occur. It is here that the argument ranged over the whole field of the common law definition of murder since Coke's Institutes (1797), the necessary intention for murder $\left(R_{v}\right.$ Woollin [1999] 1 AC 82 ), when and if the sacrifice of one human being for the benefit of another could ever be made (see $R v$ Dudley \& Stephens (1884) 14 QBD 273), and when the doctrines of necessity and/or quasi-self-defence could apply. On this aspect I shall content myself with the point that this argument revolved around the peculiar facts of this case, stemming from the starting point that although the one twin was dependent upon the other as I have described both were separate lives in being requiring the protection of the law. In the result, an English court for the first, and possibly only, time sanctioned a surgical procedure to a patient (Mary) which (i) did not confer, nor was intended to confer, any benefit upon her and (ii) to the knowledge of the doctors involved would necessarily cause her death in the course of the procedure or immediately thereafter. The alternative, not to separate or only to separate when both were on the point of death, would have led to the death of both. On top of all this and faced with this dilemma the Court of Appeal considered the human rights aspects, and hardly surprisingly found that the Convention 
rights did not provide any simpler resolution to this dilemma. How the grounds given for this decision fit into or are consistent with the general principles established in Bland and Pretty remains a subject for argument.

\section{CONCLUSION}

In bringing these remarks to a close, I should reflect upon the fact that the material I have covered is largely judge-made law under the inherent jurisdiction or within the parameters laid down in the Children Act. This is territory in which legislators in Parliament fear to tread.

I should look forward at least to what legislative developments we can expect. I do not expect within the reasonably foreseeable future legislation on euthanasia and assisted suicide. Equally, I do not expect legislation at all in the area covered by the Bland judgment. On the other hand, there is clearly in the offing a reform of the Mental Health Act. Moreover, there has been flagged up possible legislation on decision-making on behalf of mentally incapacitated adults promoted by the Lord Chancellor, but the timing of which remains uncertain. This latter legislation, if it comes, is likely to touch upon a number of themes discussed here. In particular, the proposed new scheme for Continuing Powers of Attorney (as opposed to the current Enduring Powers of Attorney) will allow individuals to delegate decision-making in respect of healthcare and welfare issues in addition to matters relating to their property and financial affairs. It will for the first time in England and Wales provide a statutory framework for welfare decision-making on behalf of an incapacitated adult (including a statutory definition of capacity and guidance as to best interests), and will give a wider jurisdiction to a regional Court of Protection over the person of a mentally incapacitated patient. That legislation, however, is likely to steer clear of the life and death issues we have discussed. In his Policy Statement Making Decisions (published in October 1999) the Lord Chancellor has indicated that one aspect of the Law Commission's recommendations in their Report 'Mental Incapacity' (Law Com. 23, published in February 1995) he will not be putting to Parliament is in relation to advance statements about healthcare.

We can, in any event, expect this to be an area in which the courts will continue to develop the law in accordance with the justice of a case in line with the principles I have described.
Laurence Oates, Official Solicitor

This article is taken from a lecture given by the Official Solicitor for the Society of Advanced Legal Studies on 24 January 2002

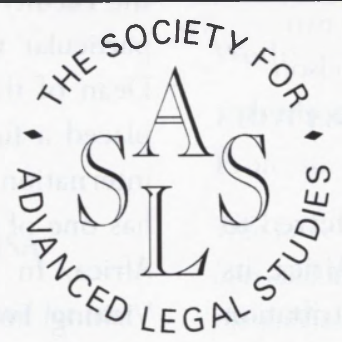

\section{THE SOCIETY FOR ADVANCED LEGAL STUDIES}

\section{NOTICE OF AGM}

NOTICE is hereby given that the Annual General Meeting of the Society will be held at the Institute for Advanced Legal Studies, Charles Clore House, 17 Russell Square, London, WC1B 5DR on Wednesday 12th June 2002 at 5.00 pm for the transaction of the following:

1. To receive and approve the annual report of the Executive Committee on the Society's activities.

2. To receive and approve the accounts for the year ending 31 May 2001.

3. To re-appoint Knox Cropper as auditors and authorise the Executive Committee to fix their remuneration.

4. To consider nominations for and to make appointments to the Executive Committee.

5. Any other business.

\section{BY ORDER OF THE EXECUTIVE COMMITTEE}

Notes:

The annual report and accounts will be available for inspection by members on 12 June. The annual report will also be available on the Society website: http://ials.sas.ac.uk/SALS/society.htm

A member entitled to attend and vote at the meeting is entitled to appoint a proxy to attend and vote instead of him/her; a proxy need not be a member. 